\title{
Positive parenting: link with the child's mental health
}

\begin{abstract}
Compliance with the fundamental principles of equality and non-discrimination, the right to privacy, autonomy, the right to information that are enshrined in international agreements and the Universal Declaration of the Rights of the Child is the beginning of the promotion of good mental health for the child.
\end{abstract}

Objective: to emphasize the relationship of parental behavior in the child's mental health.

Methodology: exploratory study within the scope of the theme in order to emerge contributions in improving children's mental health.

Results: A positive parenting with healthy interaction, security and good behavior management are undoubtedly promoters of good mental health.

Conclusion: The training of parents as caregivers, an example of a child's learning through imitation processes.

Keywords: positive parenting, child, mental health
Volume 4 Issue 5 - 2020

\section{Celeste Antão}

Instituto Politécnico de Bragança, Campus de Santa Apolónia, Bragança, Portugal

\section{Correspondence: Celeste Antão, Instituto Politécnico de Bragança, Campus de Santa Apolónia, Bragança, Portugal, UICISA: E-Higher School of Health, Email celeste@ipb.pt}

Received: August 23, 2020 | Published:September 14, 2020

\section{Introduction}

Mental health problems affect about 1 in 10 children and young people (FMH, 2020). ${ }^{1}$ Furthermore, $7.4 \%$ of children aged 3-17 years have diagnosed behavior problem (CDC, 2010). ${ }^{2}$ Depression, anxiety and behavioral disorders are included and the relationship between positive parenting has been shown in many studies. The pivotal role of parents and family in the management of the child's behavior is recognized, as well as of the PHC professionals in supporting parenting. ${ }^{3}$ Ability to adapt to new circumstances of life/changes. Having mental health is overcoming crises and resolving emotional losses and emotional conflicts; be able to recognize limits and signs of discomfort; critical sense and reality, humor, creativity, ability to dream, establish satisfactory relationships with other members of the community and have life projects, ${ }^{4,5}$ using the theory of social learning, point out that children's behavior is shaped by the behavior that they observe in their caregivers and that their responses to children's behavior influence the likelihood that children will behave this way in the future more or less frequently. The promotion of the child's mental health begins at the beginning of the life cycle, reflecting on the adaptation and satisfaction with which one grows and the ability to resolve adversities.

\section{Positive parenting}

The exercise of parenting functions depends on a set of variables, namely, the developmental history of the parents; the personality and psychological resources; individual characteristics of the child; the relationship between parents and the context in which it develops. Childhood mental health means reaching emotional and developmental milestones and learning healthy social skills and how to deal with problems (CDC, 2020). ${ }^{2}$ It is a state of successful performance of the mental function, resulting in productive activities, in the relationship with other people and in the ability to adapt to changes and to face challenges. Mental health is essential for personal well-being, family and interpersonal relationships and the ability to contribute to the community or society. ODPHP $(2020){ }^{6}$

\section{Parents: a firm anchor}

The parental function is symbolically represented even in the physical absence of one of the parties. The child does not exist without a family; when a child is born, a mother and father are also born and the bond is established by affection. At birth, you need the love and trust of your parents, but you also need to learn the rules and values of the society where you live. In the family, as the nucleus of society, the foundations of citizenship values are soon built (DGS, 2020). ${ }^{4}$ Recognizing the importance of parenting, the Council of Europe, ${ }^{7}$ in one of its publications, highlights as strategies that promote positive parenting, parental education, preparation courses for birth, health education and the provision of information about child development, among others, privileging not only risk factors, but above all the protective factors for the positive performance of the parental role, in a salutogenic perspective.

\section{Strategies that promote mental health}

As popular wisdom says, no one is born taught, however, when a child is born, parents may be more or less able to make decisions. The health technicians, in particular the doctors and nurses, when advising/informing/ clarifying effectively, make parents more capable of parenting and with less need to use differentiated services to deal with the behavioral challenges posed by their children. It is also important to minimize anxieties and enhance protective behaviors. Be attentive to your needs and singularities. Encouraging it, recognizing its potential, its weaknesses and difficulties is fundamental. It is not enough to give advice, it is more important to set an example. Defining rules and transmitting them in a clear, perceptible way is essential (DGS, 2020). ${ }^{4}$ Relaxing, fun, routine learning activities, getting enough sleep and eating well are fundamental to good mental health (CDC, 2019). ${ }^{2}$

The research that reveals that some people who develop mental illness in adulthood, manifested signs or had critical episodes during childhood. Although some mental illnesses cannot be prevented, their impact can be reduced and the quality of life can be improved (DGS, 
2020). ${ }^{4}$ Science has shown that a child's brain needs love and affection more than anything else. Until some time, parents spent many years in extended families, learning the skills of parenthood through osmosis of an entire extended family, as well as having responsibilities for their younger siblings. Today, few parents have the opportunity to be involved early in life in extended families (Figure 1). ${ }^{8,9}$

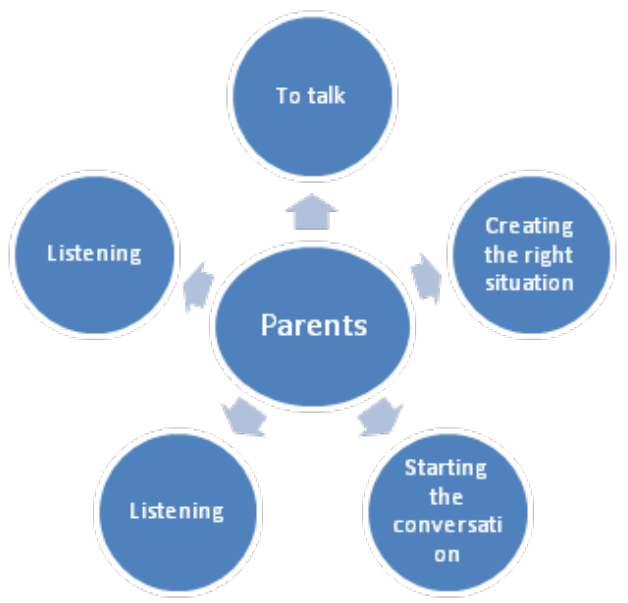

Figure I Behaviors of parents who promote mental health in children Source: adapted from NSPCC (2020): Talking about difficult topics.

\section{Discussion \& conclusion}

Promoting infant mental health is both a serious task and an opportunity. Assessment, observation, and referral to parents resources will make a difference in your youngest patients' lives and well-being. As the child grows and develops, there are many things that parents can do to help their child and thus promote their mental health. Bearing in mind that children's mental health means reaching emotional milestones, parents in their developmental journey, are those who best know the child's abilities and obstacles and consequently those who have the best conditions in promoting good mental health.

\section{Acknowledgments}

None.

\section{Conflicts of interest}

The author declares there is no conflict of interest.

\section{References}

1. FMH. Children and young people. 2020

2. CDC. Helping Children to Overcome. 2019.

3. Sousa DN. Training on parenting in Primary Health Care: Survey of needs and impact assessment on the (in) formal networks of professionals (Master's thesis). 2016.

4. DGS. Porque se fala em saúde mental? 2020.

5. Ryan R, O'Farrelly C, Ramchandani P. Parenting and child mental health. London Journal of Primary Care. 2017;9(6):86-94.

6. ODPHP. Healthy People 2030 - Building a healthier future for all. 2020.

7. Council of Europe. Parenting in contemporary Europe: a positive approach. Strasbourg: CE. 2017.

8. Winston R. Chicot R. The importance of early bonding on the long-term mental health and resilience of children. London Journal of Primary Care. 2016;8(1):12-14.

9. CDC. Children `s mental health. 2020. 